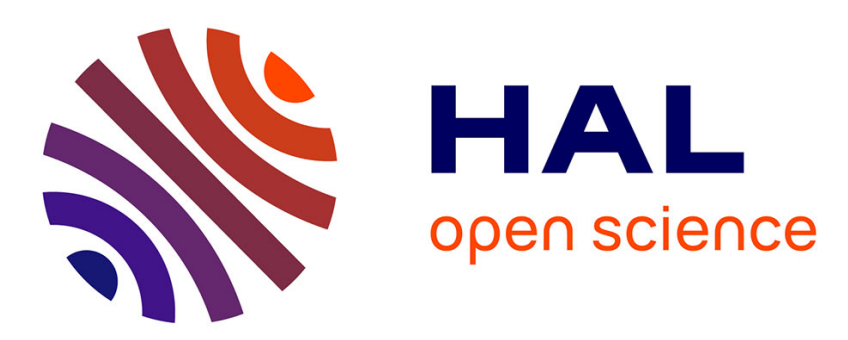

\title{
Does the accessibility measure influence the results of residential location choice modelling?
}

Ioannis Baraklianos, Louafi Bouzouina, Patrick Bonnel, Hind Aissaoui

\section{To cite this version:}

Ioannis Baraklianos, Louafi Bouzouina, Patrick Bonnel, Hind Aissaoui. Does the accessibility measure influence the results of residential location choice modelling?. 2018. hal-01801379

\section{HAL Id: hal-01801379 \\ https://hal.science/hal-01801379}

Preprint submitted on 28 May 2018

HAL is a multi-disciplinary open access archive for the deposit and dissemination of scientific research documents, whether they are published or not. The documents may come from teaching and research institutions in France or abroad, or from public or private research centers.
L'archive ouverte pluridisciplinaire HAL, est destinée au dépôt et à la diffusion de documents scientifiques de niveau recherche, publiés ou non, émanant des établissements d'enseignement et de recherche français ou étrangers, des laboratoires publics ou privés. 
Does the accessibility measure influence the results of residential location choice modelling?

Ioannis Baraklianos

Univ Lyon, ENTPE, LAET, France

Louafi Bouzouina

Univ Lyon, ENTPE, LAET, France

Patrick Bonnel

Univ Lyon, ENTPE, LAET, France

Aissaoui Hind

Univ Lyon, ENTPE, LAET, France

Corresponding author:

Ioannis Baraklianos, Univ Lyon, ENTPE, LAET, F-69120, VAULX-EN-VELIN, France

Email: ioannis.baraklianos@entpe.fr

ORCID ID : https://orcid.org/0000-0003-4320-8509 


\section{Abstract}

Accessibility is essential in Land-Use Transport Interaction (LUTI) framework. For residential location choice in particular, it has always been important at theoretical level. At empirical level, the place of accessibility is doubt in some case studies, considering other location characteristics more important, like the social environment and the neighbourhood amenities. However, this result can be caused by the measurement of accessibility. In view of the wealth of approaches, this paper examines whether different accessibility measures can lead to divergent results. Using a residential location choice model for the Lyon urban area, we test various accessibility indicators and we compare the results. Accessibility is an indispensable variable, whatever is the measure. Without it, the model gives inconsistent results. Complex accessibility measures give better results but simple measures are also relevant for residential location choices modelling. The choice depends heavily on the objectives of the application especially if the model is to be used for simulation.

Keywords

Accessibility measurement; residential location choice modelling; MNL model; Lyon urban area; LUTI

\section{Introduction}

Accessibility is central to Land-Use Transport Interaction (LUTI) models (Acheampong and Silva, 2015; Bonnel et al., 2013; Zondag et al., 2015), playing an important double role. On the one hand, it is one of the main results of the simulation process, facilitating the decision-making. On the other hand, it is one of the key variables in the location choice models of households and firms as it expresses the main effect of the transport system (Zondag et al. 2015) quantifying the potential interaction between land use and transportation system (Hansen 1959).

At theoretical level, accessibility is an important determinant in residential location choice models (Alonso 1964; Lowry 1964). In empirical models however, a significant relation between accessibility and residential location choice is rather hard to be proven (Blijie 2005; Lee et al. 2010). Some studies 
have questioned the importance of accessibility concluding that other location attributes like social environment, neighbourhood amenities and dwelling characteristics are more important (Blijie 2005; Sener et al. 2011; Zondag and Pieters 2005). Others, consider accessibility as essential in the estimation of residential location choice models (Eliasson, 2010; Srour et al., 2002) and conclude that accessibility is important even in a polycentric urban structure (Lee et al., 2010). Many factors can contribute to these divergent results like the modelling choices (analysis level, explanatory variables, model structure and market segmentation) or the local particularities (in areas where the transport services are good, the importance of accessibility tends to decrease). These controversial results might be explained by the fact that the definition and measurement of accessibility has not been thoroughly examined in LUTI literature.

In the context of the residential location choice, a great variety of accessibility measures is applied (Schirmer et al. 2014), from simple to complex ones. A simple definition can be the proximity to transport infrastructure or a Euclidian distance of a location to the city centre, as it was implemented in the first works of Alonso (1964). More complex definitions of accessibility, integrate the individual taste, preferences and capabilities to travel and are based on more advanced modelling techniques. However, "accessibility is often a misunderstood, poorly defined and poorly measured construct" (Geurs and van Wee, 2004, p. 127). Translating its influence in residential location choice context, where the decision depends on various dimensions can be a complex task. Measurement choice of accessibility can potentially influence the conclusions that one draws on the importance of accessibility.

Recent researches have questioned the sensitivity of the modelling results to the accessibility measure in other frameworks. Boisjoly and El-Geneidy (2016), using public transport share regression models, analysed the influence of time sensitive accessibility measures to the results of modal choice modelling. Bunel and Tovar (2014), in the framework of spatial mismatch, examined if the results of local job accessibility modelling depend on the measurement strategy. But in the context of the residential location choice modelling, to our knowledge, little research have analysed the effect of the accessibility measure. One exception is the work of Srour et al. (2002) for Dallas-Fort Worth, who 
applied two different accessibility measures (cumulative opportunities and logsum from a trip-based model) to three activities (work, park, shopping).

Our objective is to extent Srour et al. (2002) work, analysing the influence of accessibility measurements on the results of a residential location choice model. More precisely we would like first to confirm the importance of accessibility measurement, even if very simple definitions are used, in residential location choice model, and secondly to assess the benefit of using more sophisticated measurement of accessibility. We developed an empirical application for the urban area of Lyon. Our application is based on previous works which allowed to develop a residential location choice (Aissaoui et al. 2015; Kryvobokov and Bouzouina 2014).

Usually, the decision on the best accessibility measurement is based on model statistical indicators. In our work, we will both analyse model statistical indicators but also market share predictions of location choices. When developing models for planning it is important to get good statistical indicators but also to reproduce correctly observed market share. Our work aims to provide guidance to modellers and decision makers on making better and faster decisions regarding the use of accessibility in residential location choice modelling.

The rest of the paper is structured as follows. Section 2 presents accessibility theory in the framework of residential location and applied measurement methods used in residential location choice. Section 3 presents the study area, the data, the accessibility measures, the residential location choice model and our evaluation strategy. Section 4 presents the modelling results while the last 2 sections outline the discussion of the results and the conclusions of the article.

\section{Accessibility and residential location choice: one concept, different}

\section{approaches, different results?}

The concept of accessibility is difficult and complex due to the fact that it is a multicomponent and a multidimensional construct (Boisjoly and El-Geneidy, 2016; Cascetta et al., 2016; Geurs and van Wee, 
2004; Niedzielski and Boschmann, 2014) for which the measurement methods are not yet standardised (Acheampong and Silva 2015).

The accessibility is a construct of three components, transportation, activities and individuals (Niedzielski and Eric Boschmann 2014). Those three components evolve in two dimensions, in space and time (Geurs and van Wee 2004). Initially, accessibility was not conceived as a multicomponent and multidimensional concept. It was merely a two-component concept within the spatial dimension (Hansen 1959), defined as the interaction between transport and land use. Further research then highlighted the importance of individual component (Ben-Akiva and Lerman, 1985) and temporal dimension (Hägerstrand 1970). Accessibility gains on theoretical developments were posterior to advances of empirical methods in several fields, particularly in economics and geography. This led to a fragmentation of the applied methods, points of view, methodological processes and assumptions ${ }^{1}$.

Residential location choice is heavily influenced by accessibility. Areas with high accessibility provide a better quality of life (Niedzielski and Eric Boschmann 2014). Households can make shorter and more optimised travels due to trip-chaining (Hu 2017). Different components can have different influence on residential locations. Transport infrastructure could be an opportunity for household members as it increases their ability to travel. However, it can create negative externalities such as pollution, which can discourage a household from locating in close proximity. Such long-term decisions, as residential location, are affected by the spatial distribution of the activities in which household's members participate like employment, shopping and leisure (Wegener and Fürst 1999). More opportunities easily accessible increases potential activity participation, especially for nonmandatory purposes (Cordera et al. 2017). Individual preferences and capabilities influence activity participation and transportation preferences. The access to spatially distributed opportunities from a residential location and the potential need for travel are related to individual caracteristics (Ben-Akiva and Lerman 1985; Wegener and Fürst 1999). All these choices are constrained by the individual space-time activity prism (Hägerstrand 1970), which limits the ability of individuals to participate in all desired activities within the space and the time of the day.

\footnotetext{
${ }^{1}$ For a review on the contrasts of the accessibility approaches see Niedzielski and Eric Boschmann (2014)
} 
Translating these components and dimensions of accessibility into indicators is not an easy task. Accessibility indicators that incorporate individual component and temporal dimension, require data and modelling techniques that are not always available. In residential location choice literature, the transport and land use components are integrated through location-based accessibility measures (distance to centre, cumulative opportunities, potential accessibility), which capture mostly the spatial dimension of accessibility. The individual component is integrated either by interacting location-based accessibility measures with households characteristics or by using logsum accessibilities derived by trip-based or activity-based transportation models ${ }^{2}$. The temporal dimension is integrated usually within the transport component (peak-on times). In Table 1, we present some empirical studies of residential location choice models to illustrate the diversity of the measures and the conclusions on the importance of accessibility. We have not set out to be exhaustive but to give some representative recent research, which illustrates our research question.

In Paris (De Palma et al. 2007), the distance to motorways and the number of railway and subway stations were significant when the analysis was made at commune level while they were not when the model was calibrated at grid cell level. Distance to the centre was significant only when analysis was conducted at commune level. The authors highlighted that the accessibility to transport infrastructures is more important than the negative externalities they can cause. In Dallas-Fort Worth, Srour et al. (2002) using logsum accessibilities and cumulative opportunities measures, found that accessibility employment is more important than accessibility to shopping and parks and concludes that cumulative opportunities measure is the most appropriate. For the same study area, Guo and Bhat (2007) found that the perception of accessibility can vary based on the households characteristics. In general, accessibility to employment has negative impact on a location choice, but higher income and oneindividual households tend to choose locations with good accessibility to employment. Eliasson (2010), using logsums, calculated by activity-based model for Stockholm, found that the attractiveness of a location was positively influenced by the accessibility to workplaces and to other activities like services, shopping etc. The author concludes that accessibility is key in location choice models but one

\footnotetext{
${ }^{2}$ For a general review of accessibility measures see Geurs and van Wee (2004) and for a review of the accessibility measures applied in residential location choice models see Schirmer et al. (2014)
} 
must include it to various activities and not only to employment. Cho et al. (2008) using a logsum accessibility to 10 different employment centres in Mecklenburg County, a polycentric urban form, found that in general accessibility to employment is a determinant factor for a residential location choice. Then, using market segments by income, they found that households appreciate accessibility to different employment centres depending on the specialization of the centre. Lee et al. (2010) in their application for the Puget Sound region, found that the logsum of trips to work, estimated by an activity-based transport model, was significant for residential location choice, even after controlling for other location, neighbourhood and dwelling attributes. Additionally, to our knowledge, this was the only application that have integrated a space-time measure in a residential location choice model. They used the opportunities-based approach ${ }^{3}$ and found that the shopping opportunities on the work-tohome trip had a significant influence. The fact that this type of measure is not commonly applied in residential location choice modelling may be due to empirical difficulties (Boisjoly and El-Geneidy 2016; Cascetta et al. 2016; Geurs and van Wee 2004).

Some studies question the importance of accessibility for residential location choice. In the Netherlands, Blijie (2005) found that the distance to motorway ramps was significant for three household types and that the household's car ownership influences this sensitivity. At the same time, the distance to a railway station was significant for only one household type. The author argues that accessibility has only a marginal influence on residential location choice. Zondag and Pieters (2005), for the same study area and using similar modelling approach (market segments), found that activitybased logsums for work and education trips did not have significant influence. However, the logsums for "all trip purposes" or "other trips" were significant but only for some household types. Their final conclusion is that accessibility has a minor influence on residential location choice. Sener et al. (2011), using two different modelling strategies (Multinomial logit and Distance-based Spatially Correlated logit), in their application for the San Francisco Bay Area, found that zonal motorway density was significant only when the Multinomial logit model was used, while the household commute time to work (the sum of working household members) had always significant negative influence. Moreover,

\footnotetext{
${ }^{3}$ For a review of space time accessibility measures see Cascetta et al. (2016)
} 
the number of household members with work location within 30 minutes by Public Transport is positive and significant. However, they found that location-based accessibility measures were insignificant, without specifying the applied accessibility measure. The study for the Dallas-Fort Worth metroplex (Guo and Bhat 2001), using potential accessibility measures to employment, shopping and leisure opportunities, found that only accessibility to shopping opportunities was significant for all households while the other two were sensitive to household characteristics (education level of the head and the race of the household). They conclude that accessibility to general employment is not important except for the educated workers.

In this paper, we set a threefold objective. First, we test various measures to examine if accessibility influences the location choice modelling results. The existing studies have applied many different accessibility indicators to different contexts, so their results are not comparable. Potentially, accessibility measures can influence this result. Second, we analyse to what extend different households appreciate accessibility differently and how this fact affects the modelling results. Third, we examine the ability of the model to replicate the observed choices. This indicator of model quality is important when the model is to be used for planning purposes even if not often used in literature. 
Table 1 Literature review summary

\begin{tabular}{|c|c|c|c|c|c|c|c|}
\hline Source & Study area & Model structure & $\begin{array}{l}\text { Multiscale } \\
\text { analysis }\end{array}$ & Market segmentation & Accessibility measures & $\begin{array}{l}\text { Interaction accessibility } \\
\text { with household } \\
\text { characteristics }\end{array}$ & Conclusion \\
\hline Blijie, 2005 & The Netherlands & Multinomial Logit & No & 6 groups & $\begin{array}{l}\text { Distance to railway stations } \\
\text { and to motorway ramps }\end{array}$ & Car ownership & $\begin{array}{l}\text { Accessibility has marginal } \\
\text { influence }\end{array}$ \\
\hline $\begin{array}{l}\text { De Palma et al., } \\
2007\end{array}$ & $\begin{array}{l}\text { Ile-de-France } \\
\text { (Paris region) }\end{array}$ & Multinomial Logit & Yes & No & $\begin{array}{l}\text { Number of railway and } \\
\text { subway stations, distance to } \\
\text { motorways, distance to city } \\
\text { centre }\end{array}$ & N/A & $\begin{array}{l}\text { Accessibility to transport } \\
\text { infrastructure important }\end{array}$ \\
\hline Sener et al., 2011 & $\begin{array}{l}\text { San Francisco } \\
\text { Metropolitan Area }\end{array}$ & $\begin{array}{l}\text { Multinomial Logit, } \\
\text { Spatially Correlated } \\
\text { Logit }\end{array}$ & No & No & $\begin{array}{l}\text { Location-based } \\
\text { accessibility, zonal } \\
\text { motorway density }\left(\mathrm{km} / \mathrm{km}^{2}\right) \text {, } \\
\text { number of household } \\
\text { members with work location } \\
\text { in } 30 \text { minutes or less by } \\
\text { Public Transportation }\end{array}$ & N/A & $\begin{array}{l}\text { Location-based } \\
\text { accessibility measures } \\
\text { were insignificant }\end{array}$ \\
\hline $\begin{array}{l}\text { Guo and Bhat, } \\
2007\end{array}$ & $\begin{array}{l}\text { Dallas-Fort Worth } \\
\text { metroplex }\end{array}$ & Multiscale Logit & Yes & No & $\begin{array}{l}\text { Potential accessibility to } \\
\text { employment, shopping and } \\
\text { recreation }\end{array}$ & $\begin{array}{l}\text { Household income, } \\
\text { number of household } \\
\text { members }\end{array}$ & $\begin{array}{l}\text { Accessibility to } \\
\text { employment significant, } \\
\text { different households have } \\
\text { different sensibility }\end{array}$ \\
\hline Srour et al., 2002 & $\begin{array}{l}\text { Dallas-Fort Worth } \\
\text { metroplex }\end{array}$ & Multinomial Logit & No & No & $\begin{array}{l}\text { Cumulative opportunities } \\
\text { and logsum (trip-based) } \\
\text { accessibilities to } \\
\text { employment, to shopping } \\
\text { and to park space }\end{array}$ & N/A & $\begin{array}{l}\text { Accessibility is a major } \\
\text { explanatory variable }\end{array}$ \\
\hline Eliasson, 2010 & Stockholm region & Nested Logit & No & No & $\begin{array}{l}\text { Logsum (activity-based) for } \\
\text { work and other trips } \\
\text { Logsum (activity-based) to }\end{array}$ & N/A & $\begin{array}{l}\text { Accessibility is key in } \\
\text { location choice models }\end{array}$ \\
\hline $\begin{array}{l}\text { Zondag and Pieters, } \\
2005\end{array}$ & The Netherlands & Nested Logit & No & 6 groups & $\begin{array}{l}\text { work, education and other } \\
\text { trips }\end{array}$ & N/A & $\begin{array}{l}\text { Accessibility has a minor } \\
\text { influence }\end{array}$ \\
\hline Lee et al., 2010 & Puget Sound Region & Multinomial Logit & No & No & $\begin{array}{l}\text { Cumulative opportunities to } \\
\text { shopping, logsum (activity- } \\
\text { based) for work trips, log on } \\
\text { shopping in time-space } \\
\text { prism for work to home } \\
\text { trips }\end{array}$ & N/A & $\begin{array}{l}\text { Accessibility was } \\
\text { significant for residential } \\
\text { location choice, even after } \\
\text { controlling for other } \\
\text { location, neighbourhood } \\
\text { and dwelling attributes }\end{array}$ \\
\hline
\end{tabular}




\section{Methodology and data}

\section{Study area}

Lyon urban area is the second most populated urban area in France after Paris. In total, the urban area had more than 750,000 jobs in 2006 , of which more than $40 \%$ were concentrated in the area's central municipalities (Lyon-Villeurbanne) and almost 75\% inside so-called "Grand Lyon", which is made up of the city of Lyon and some suburbs (fig. 1).

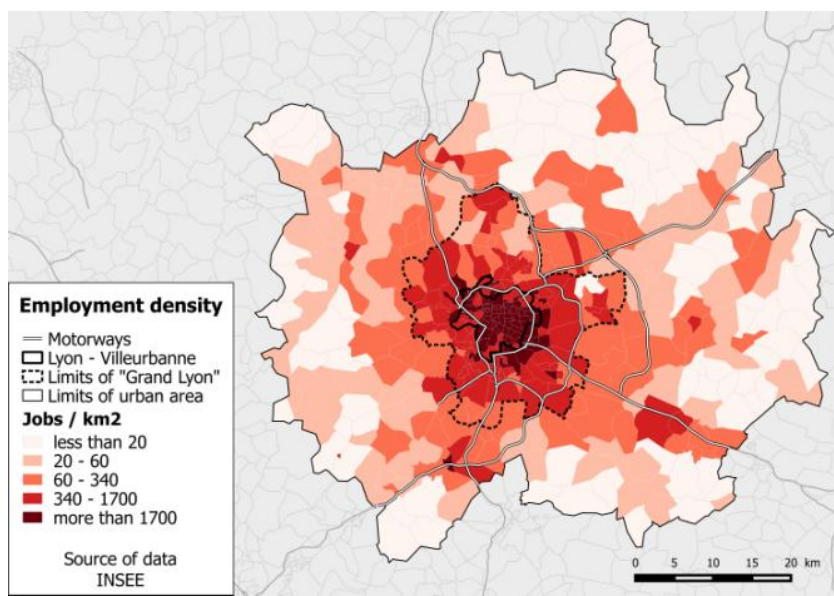

Fig. 1 Employment density of the study area by zone (classification in quantiles)

\section{Data}

To apply our methodology, we combined different disaggregated databases. For the calculation of the accessibility indicators, we used generalised times and the employment. The generalised times by car and public transport along with the parameters for the estimation of the accessibility indicators (parameter $\beta$ in equation 5) were calculated by a transportation model developed in LAET (Laboratoire, Aménagement, Economie, Transport - Transport, Urban Planning, Economics Laboratory) for the Lyon urban area. The model is a traditional 4-step trip-based transportation model with some original enhancements (Nicolas 2010). The model has been calibrated using 2006 household travel survey data. The number of jobs per zone was calculated using the official INSEE (Institut National de la Statistique et des Etudes Economiques - French National Institute of Statistics and Economics Studies) company register (SIRENE database) which is a disaggregated database that contains all the economic establishments in France. The other accessibility indicators were calculated using Geographic Information Systems. For the estimation of the residential location choice model we 
used the data of 103,256 recently moved households (2006-2008) from disaggregated census data of 2008.

\section{Accessibility indicators}

We consider accessibility as a location characteristic. We use simple indicators, like the proximity to transportation infrastructure, or more complex ones, like the potential accessibility. Concerning activity to which the accessibility was estimated, we retained only the general employment for two reasons. Firstly, accessibility to employment is central to residential location choice modelling at both theoretical (Alonso 1964; Lowry 1964) and empirical levels (Guo and Bhat, 2007; Wegener and Fürst, 1999). It influences the prospect of residents finding a job, facilitates activity participation and affects the quality of life (Hu 2017; Niedzielski and Eric Boschmann 2014). Secondly, for our study area, the number of jobs and thus accessibility to employment is highly correlated with shopping or leisure activities (see table 2). In all cases the correlation of the number of jobs is higher than 0.75 , so correlation between accessibilities can be much higher depending on the measure.

Table 2 Correlation of the number of jobs by zone

\begin{tabular}{cccc}
\hline & Employment & Shopping employment & Leisure employment \\
\cline { 2 - 4 } Employment & 1.00 & 0.76 & 0.77 \\
Shopping employment & 0.76 & 1.00 & 0.79 \\
Leisure employment & 0.77 & 0.79 & 1.00 \\
\hline
\end{tabular}

When we have multiple transport modes serving an area, we have to aggregate measures by mode in order to calculate a composite accessibility. Usually, the aggregation is performed at the impedance (Geurs and Ritsema van Eck 2001). For the aggregation of the generalised times, we applied a method developed by Bhat et al. (1999). The result is a composite generalised time, which combines times by car and Public Transportation (PT). This formulation was chosen because it is compatible with the concept of accessibility; the increase in transportation solutions is associated with an increase of accessibility (Handy and Niemeier 1997). The idea is when an Origin-Destination (OD) pair is served by both car and PT, the impedance should be less than the faster mode. This is because more transportation solutions give more mobility options and it is easier to commute between this OD. Thus, accessibility should be higher. On the contrary, when there is no PT service, only the option of 
the car is available and composite generalised time is equal to the generalised time by car. There are other methods as well which give composite impedance, like the combination of modes using market shares or keeping only the fastest mode. However, the retained method is theoretically consistent with the concept of accessibility and gives the best results in the residential location choices context. The generalised time by car is the reference time for all pairs of OD. Depending on the availability of modes, the composite generalised time is given by equation 1 (only car available) or by equation 2 (both options available).

$$
\begin{aligned}
& T c_{i j}=\operatorname{Tcar}_{i j} \\
& T c_{i j} \text { : Composite generalised time from } i \text { to } j \\
& T c_{i j}=\left(\frac{\operatorname{Tcar}_{i j}}{1+\frac{\text { Tcar }_{i j}}{T p t_{i j}}}\right) \\
& \text { Tcar }_{i j} \text { : Generalised time for car } \\
& \text { Tpt }_{i j} \text { : Generalised time for PT }
\end{aligned}
$$

The selection of the measures was made in order to progressively improve the accessibility quality measurement. The applied measures are:

- Proximity to transportation infrastructure

- Proximity to motorways, metro, tramway or railway station as dummy variable that takes the value 1 if the zone disposes one station or a motorways passes through, otherwise is 0

- The linear distance from the centroid of each alternative zone to the centre (equation $3)$.

$$
\begin{aligned}
& A_{i}=d_{i j} \\
& j=\text { city centre }
\end{aligned}
$$

- Generalised time to access by car to city centre (equation 4).

$$
\begin{aligned}
& A_{i}=T c_{i j} \\
& j=\text { city centre }
\end{aligned}
$$

- Generalised time to access by car to secondary centres (see fig. 2) 


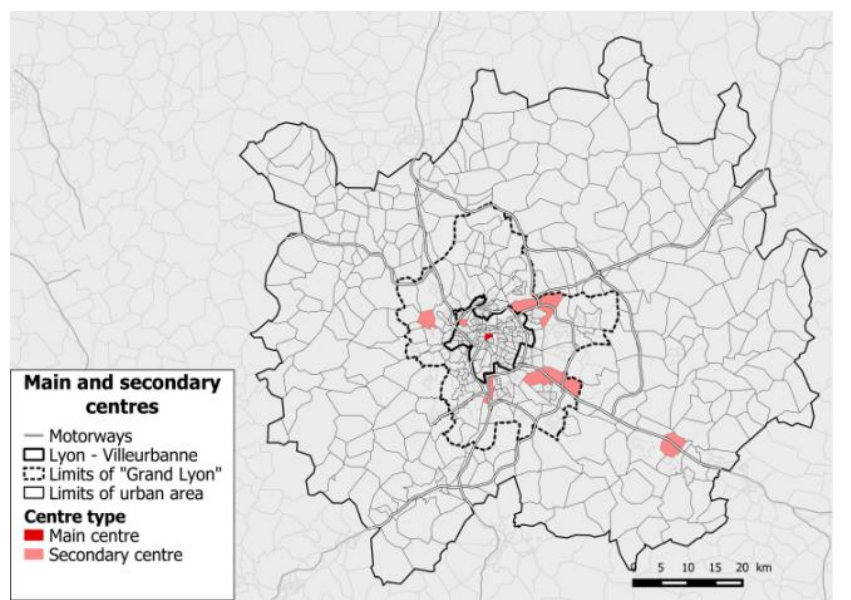

Fig. 2 Main and secondary employment centres of the urban area of Lyon

- Cumulative opportunities to employment by car, i.e. the sum of the employment opportunities reachable in 30 minutes (equation 5). In Lyon the mean home-to-work travel time by car in 2006 was 23 minutes (Sytral 2007). A threshold of 30 minutes is retained, which is the most common in similar studies (Srour et al. 2002; Waddell 2010).

$$
\begin{aligned}
& A_{i}=\sum_{j} D_{j} f_{(j)} \\
& f_{(j)}=1 \text { if } \text { Tcar }_{i j} \leq 30, \text { otherwise } 0
\end{aligned}
$$

- Potential accessibility to employment i.e. the sum of the number of employment opportunities $D$ at location $j$ weighted by an impedance function. Two impedance functions are retained:

- Linear distance as impedance factor (see equation 6.1).

- A negative exponential impedance function using generalised times by car and by PT (see equation 6.2), with a $\beta$ value of 0.12 for car and 0.10 for PT calibrated using the household travel survey (Bouzouina et al. 2014). This indicator is used with simple generalised times (separate accessibilities by car and PT) and composite generalised times (equation 2).

$$
\begin{aligned}
& A_{i}=\sum_{j} D_{j} \frac{1}{d_{i j}} \\
& A_{i}=\sum_{j} D_{j} e^{-\beta T c_{i j}}
\end{aligned}
$$




\section{Residential location choice model}

The modelling method used in this study is based on discrete choices (McFadden 1977). In discrete choice modelling the decision-maker selects the alternative, from an available choice set, which maximises his utility (Schirmer et al. 2014). In residential location choice, the decision-maker is the household, and the alternatives can be large zones, small neighbourhoods or even buildings. The individual utility is composed by a deterministic observable part and a random term (equation 7). The observable utility depends on the characteristics of the alternatives (zonal, dwelling etc.) or the characteristics of the individuals.

$$
\begin{array}{ll}
U_{\text {in }}=V_{\text {in }}+\varepsilon_{\text {in }} & \begin{array}{l}
U_{\text {in }}: \text { Utility of household } n \text { at location } i \\
V_{\text {in }}: \text { Deterministic part of the utility } \\
\varepsilon_{\text {in }}: \text { The error term }
\end{array}
\end{array}
$$

Our residential location choice model is a Multinomial Logit (MNL) model with 6 random choices of alternatives for every observed choice (Aissaoui et al., 2015). When there is a large number of alternatives, as it is in our case, we can estimate a MNL model using a sample of alternatives $D_{n}$ of the true choice set $C_{n}$ and get consistent parameters (McFadden, 1977). After testing for various sample sizes, we concluded that 6 is the best number of alternatives in terms of the stability of the parameters and the estimation speed.

The probability of household $i$ making the choice $n$ is given by the exponential of the utility of the observed choice divided by the sum of the exponential of the utilities of the random alternatives $j$ (Equation 8). For our modelling needs, the Lyon urban area is divided into 432 neighbourhoods ${ }^{4}$.

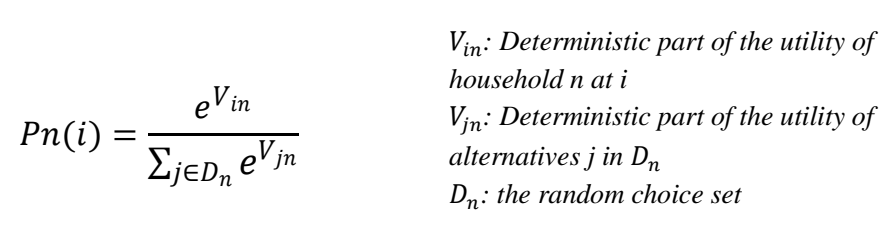

The variables of the model are divided into three categories. The first describe local spatial amenities including basic local shopping opportunities and the education services. The second describe the social environment of the neighbourhood, including variables that reveal income self-segregation effects and a proxy for endogenous amenities along with the sensitivity to social housing capturing the sensitivity

\footnotetext{
${ }^{4}$ We are following the zoning system of INSEE based on the « grand quartier » zones, which is essentially a census breakdown
} 
to social proximity. Self-segregation variables for $1^{\text {st }}$ and $2^{\text {nd }}$ quantile of revenue were not included because they are highly correlated with the social housing variables. The third category includes the variables of the market trade-off, which includes housing price and accessibility. The variables are presented in detail in Table 5.

Table 5 Variables of the residential location choice model

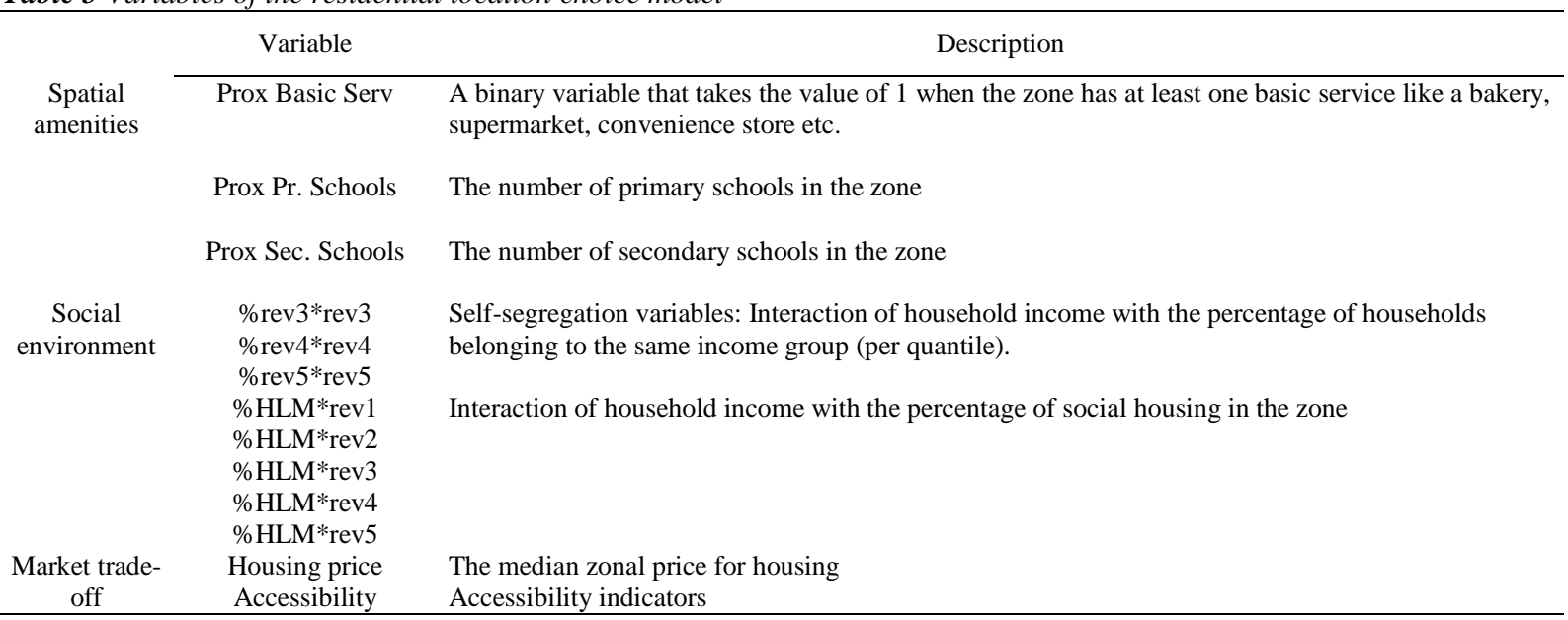

A drawback of the selected accessibility measures is their failure to integrate the individual dimension (see table 6), which is an important dimension of accessibility (Geurs and van Wee 2004) having a significant role in residential location choice. We interact certain household characteristics with accessibility measures in the location choice model in order to capture individual taste variations. The selected characteristics were: status, education level of the head of the household and household size. The same household characteristics have also been employed in other studies (Frenkel et al. 2013; Guo and Bhat 2007; Guo and Bhat 2001; Hu 2017; Millsap 2016).

Table 6 The applied accessibility measures and the estimated models 


\begin{tabular}{|c|c|c|}
\hline Base model & Model 1 & The model without accessibility measure. We use it as a benchmark model \\
\hline Transport Infr. Proximity & Model 2 & $\begin{array}{l}\text { Only proximity to various transport infrastructure is included. It is the simplest } \\
\text { method, and it takes into account only the local effect of the transport } \\
\text { component of accessibility }\end{array}$ \\
\hline Dist. to centre & Model 3 & $\begin{array}{l}\text { It is the first global measure because we have a relative value of accessibility for } \\
\text { all zones. However, the measure incorporates is a strong assumption at the } \\
\text { spatial dimension concerning both the land-use component (all employment to } \\
\text { city centre) and the transport component (homogenous space). }\end{array}$ \\
\hline Time to centre (car) & Model 4 & $\begin{array}{c}\text { Time represents better the ability to travel to the city centre. We use only the } \\
\text { generalised time by car. It relaxes the assumption of the transport component but } \\
\text { not for the land-use component. Temporal dimension is present because we are } \\
\text { referring to peak-on generalised times. }\end{array}$ \\
\hline Time to centre $+2^{\text {nd }}$ centres (car) & Model 5 & $\begin{array}{l}\text { To bypass the assumption of the influence of the main centre, we integrate a } \\
\text { secondary accessibility measure, the time to secondary centres. We maintain the } \\
\text { main centre since it must have an effect even with a presence of secondary ones. } \\
\text { This method relaxes the assumption of the spatial distribution of employment } \\
\text { opportunities, but not completely. }\end{array}$ \\
\hline Cumm. Opp. car & Model 6 & $\begin{array}{l}\text { It is a measure that relaxes the assumptions of the spatial dimension of the land- } \\
\text { use, since we do not restrict the influence only on some central areas. However, } \\
\text { the a priori definition of the contour threshold poses a strong assumption on the } \\
\text { influence of the spatial distribution of land-use. Only employment within the } \\
\text { defined threshold counts. }\end{array}$ \\
\hline Pot. Acc. Distance & Model 7 & $\begin{array}{l}\text { The potential accessibility measure overcomes the drawbacks of the cumulative } \\
\text { opportunities measure. As a first step, we integrate only the linear distance as a } \\
\text { friction. It poses a hypothesis that the transport component is homogenous in } \\
\text { space. }\end{array}$ \\
\hline Pot. Acc. car & Model 8 & $\begin{array}{l}\text { To overcome the simplicity of the linear distance as a friction, we integrate only } \\
\text { the car as a transport mean. }\end{array}$ \\
\hline Pot. Acc. car + PT & Model 9 & $\begin{array}{l}\text { We add the potential accessibility by PT in order to capture the joint effect of } \\
\text { the two means of transportation. }\end{array}$ \\
\hline Pot. Acc. Composite & Model 10 & $\begin{array}{l}\text { Because the integration of two accessibility measures creates multicollinearity, } \\
\text { we integrate a potential measure using a composite generalised time. }\end{array}$ \\
\hline Accessibility $* \mathrm{Nb}$ Indiv. & $\begin{array}{c}\text { Models } \\
3-1,7-1,8-1,10-1\end{array}$ & $\begin{array}{l}\text { In order to account for individual taste heterogeneity of accessibility, we } \\
\text { introduce various interactions between household characteristics and } \\
\text { accessibility measures. The first household characteristic is its size. The number } \\
\text { of individuals in a household defines the effect of accessibility. The biggest the } \\
\text { household, the biggest the need for space. Usually accessible areas lack on } \\
\text { available space. }\end{array}$ \\
\hline Accessibility $*$ HH Education & $\begin{array}{c}\text { Models } \\
3-2,7-2,8-2,10-2\end{array}$ & $\begin{array}{l}\text { The education level of the household head can define the preference for } \\
\text { accessibility. Highly educated individuals have a diverse activity programme } \\
\text { (Frenkel et al. 2013) and accessibility is important. }\end{array}$ \\
\hline Accessibility * HH Status & $\begin{array}{l}\text { Models } \\
3-3,7-3,8-3,10-3\end{array}$ & $\begin{array}{l}\text { The status is essential for the impact of accessibility. Students and households } \\
\text { with no stable employment status are more sensible to accessibility. They have a } \\
\text { diverse activity programme and they do not have a stable job, so high } \\
\text { accessibility to employment is essential. }\end{array}$ \\
\hline
\end{tabular}

\section{Evaluation method}

In order to evaluate and compare the results of the models according to the selected accessibility measures we implemented various indicators:

- The likelihood ratio test (equation 9), using a standard incremental approach in order to analyse the contribution of each variable to the model (Ben-Akiva and Lerman 1985).

$$
\begin{array}{ll}
L R T=-2\left(L(\hat{\beta})-L_{\delta}(\hat{\beta})\right) & L(\hat{\beta}): \text { Log-likelihood of the restricted model } \\
L_{\delta}(\hat{\beta}): \text { Log-likelihood of the unrestricted model }
\end{array}
$$


- The adjusted rho-squared which reveals the quality of the model fit.

- Analysis of the stability of the models' parameters.

- The ability to replicate the observed market shares, which is used to validate the modelling results in other applications (Cordera et al. 2017). For that, we analyse the differences between the observed market shares and the replicated ones using the Root Mean Squared Error (RMSE - equation 8) (Fox et al. 2014; Washington et al. 2011). To apply the RMSE, we aggregated the zoning system in 5 principal zones (fig. 3). It is more convenient to present the results in 5 zones and to identify the source of the error.

$$
R M S E=\sqrt{\frac{\sum_{j}\left(N_{j}-T_{j}\right)^{2}}{J}} \quad \begin{aligned}
& N_{j}: \text { Observed market share in } j \\
& T_{j}: \text { Replicated market share in } j \\
& J: \text { Number of alternative zones in } C_{n}
\end{aligned}
$$

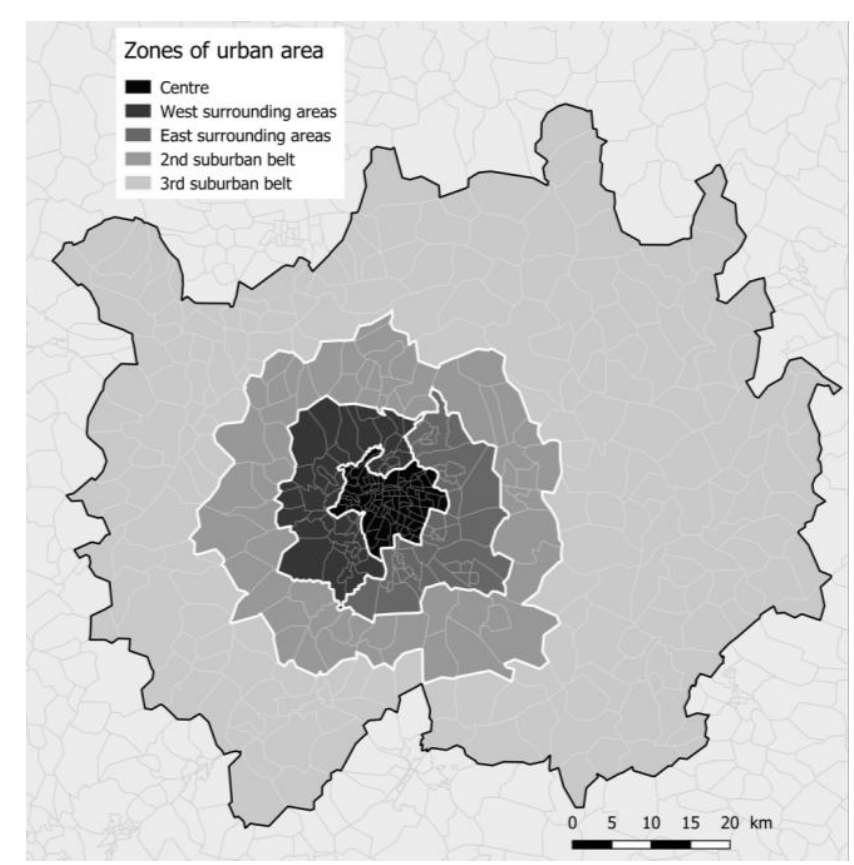

Fig. 3 The zones of the urban area retained for the RMSE analysis

\section{Analysis of the results}

In this section, we present the results of the estimated models. Tables 7 and 8 summarise the results of the models and tables 9 and 10 present the model performances to replicate the market shares. 


\section{Analysis of the model parameters}

Nearly all parameters are significant in almost all models. Accessibility affects the other variables of the model but they mostly stay significant. The parameters of proximity to spatial amenities are positive and significant and their values are relatively stable across the models. In the following, we focus mostly on the variables of accessibility and on the group of market trade-off.

In the base model, the parameter of the housing price is positive and significant, which is inconsistent (Guevara 2015). In model 2, the proximity to metro, tramway and railway stations has a positive effect, which confirms the positive effect of the presence of PT stations, while the proximity to motorways has a negative one. The latter may be due to the negative externalities of the motorways such as noise and pollution. Accessibility variables in models 3 to 10 have the expected signs (negative for distance or time to city centre and positive for cumulative opportunities and the potential accessibility measures). The parameters of the housing price is always negative and significant. It seems that the simple definition of accessibility as a proximity to transport infrastructure at local level leads to inconsistent modelling results. When we apply measures that capture the global effect of the accessibility, they give better results regarding the parameters, even simple definitions like the linear distance to city centre.

Table 8 presents the results of the models with the inclusion of individual taste variation of accessibility. We present the results for only four accessibility measures which interact with households characteristics ${ }^{5}$. The different parameter values confirm that the preference of accessibility changes depending on household's characteristics. Households with one or two individuals are more sensitive to accessibility than households with three or more individuals (models $3-1,7-1,8-1$, and $10-1$ ). Households whose head has low education level are not as sensitive to accessibility as households whose head has medium or high education level (models $3-2,7-2,8-2$, and $10-2$ ). Regarding household head status, students are the ones who are searching for areas with high accessibility, followed by the actives with no stable contract (models $3-3,7-3,8-3$, and $10-3$ ), followed by households whose head has a stable job or is not active (mostly retired). These results are

\footnotetext{
${ }^{5}$ We can provide the detailed results by request
} 
consistent for all accessibility measures. The relative sensitivity to accessibility is the same between the models, even for the ones that we have not included in table 8 .

\section{Model quality and statistical contribution of accessibility}

The likelihood ratio test is always significant, meaning that whatever is the measure, the contribution of accessibility in the model is always significant. The inclusion of secondary employment centres indicators (see Map 2) and accessibility by PT increases the quality of the model significantly as well. Last, the integration of individual taste variation has also a significant contribution.

Regarding the overall quality of the models, it increases with the improvement of the accessibility measure. The rho-squared of the model 2 (proximity to transportation infrastructure) 0.231 is smaller than models 3 to 10 whose rho-squared varies between 0.235 and 0.255 . An exception is the model 6 (cumulative opportunities). The cumulative opportunities measure is generally considered as a better accessibility measure (Geurs and van Wee 2004) than the proximity to transportation infrastructure or the distance to city centre but the rho-squared does not confirm this result. The model 7 , has the best overall rho-squared, even though in theory this indicator is inferior to the ones in models 8 to 10 . In the three last models, the inclusion of the PT as a separate indicator increases the quality of the model, from 0.251 for the model 7 and 0.252 for the model 8 . Nevertheless, the rho-squared is higher when we use a composite generalised time (0.254).

All the models with individual taste variation have higher rho-squared. The most appropriate household characteristic is the status of the household head and the second best characteristic is the size of the household. Between the models with individual taste variations, the best model in terms of rho-squared in the model 10-3, the one with the potential accessibility using the composite generalised time.

\section{Ability to replicate market shares}

In this chapter we analyse the model capability of replicating the market shares. Tables 9 and 10 present the results of the model's performance. We present for each model the difference between observed and replicated market shares and the RMSE. 
Generally, most of the models struggle to replicate the share of the city centre. There is a relation between model quality measured by rho-squared and replicated market shares, with some exceptions. Model 1 has the highest RMSE (8.87\%) meaning that it gives the worst replications. Most of the error comes from the replication of the share of the centre. When we use the proximity to transport infrastructure, the RMSE is relatively high (7.83\%). This definition of accessibility cannot replicate the attractiveness of the city centre neither and it overestimates the shares of the East and West areas. However, it achieves good replication of the $3^{\text {rd }}$ belt.

The use of distance to centre (RMSE 5.42\%) improves market shares replication in comparison with model 2. It underestimates to a lesser extent the share of the city centre (difference $-9.3 \%$ ) but it underestimates the share of the $3^{\text {rd }}$ belt. The use of the time by car to city centre, increases the performance of the model (RMSE of 3.97\%). Still the most problematic zone is the centre, but the underestimation is decreasing in comparison to previous models. Model 4 replicates better the shares of all the zones in comparison to the model 3 . We have seen previously that model 5 had higher rhosquared than model 4. However, the replication of the observations is not better, with RMSE of $4.20 \%$. This is because it increases the underestimation of the share of the centre.

The RMSE of the model 6 is $6,43 \%$, which is the second worst between the analysed models, only better than the RMSE of the model 2. It mostly fails to replicate the share of the city centre (underestimation of 11.4\%) and the share of the East Areas (overestimation of 6.6\%). Contrary to the cumulative opportunities, the potential accessibility measures give very good replicated market shares, even in the form with the linear distance as a friction parameter. The model 8 gives the best performance between the models without individual taste variations, with RMSE of 1.09. The error is equally distributed between all zones (between $1.3 \%$ and $-1.5 \%$ ). This means that there is no particular zone that poses problem. The addition of the potential accessibility by PT in model 9 , gives perfect replication for the centre ( $0 \%$ error) but it decreases the quality of replication for the West Areas and consequently the RMSE is $1.16 \%$. The model 10 was the second best in terms of model quality. However, the RMSE $(1.57 \%)$ is the worst between the potential accessibility measures. The use of the 
composite generalised time decreases the quality of the replicated market share of the centre (underestimation of 1.9\%) and of the East Areas (overestimation of 2.8\%).

The addition of individual taste variations in the model concerning the accessibility does not always increase the performance of the replication of the observed market shares. The inclusion of the household characteristics in model 3 , decreases the error of the replications in all cases. Concerning the potential accessibility measures we observe two cases. On the one hand, none of the models with the potential accessibility by distance or by car is able to give a better RMSE than the models without the household characteristics. On the other hand, the inclusion of individual taste variation in the model using the composite generalised time, increases the quality of the replicated market shares, when we use the household status, which gives the best replication between all models. However, the error is not as evenly distributed as it is using the model 8 . 
Table 7 Parameters and statistical tests of the models using all accessibility measures

\begin{tabular}{|c|c|c|c|c|c|c|c|c|c|c|}
\hline & $\begin{array}{c}\text { Base model } \\
\text { (no accessibility) }\end{array}$ & $\begin{array}{c}\text { Transport Infr. } \\
\text { Proximity }\end{array}$ & Dist. to centre & Time to centre & $\begin{array}{l}\text { Time to centre }+ \\
2^{\text {nd }} \text { centres }\end{array}$ & Cumm. Opp. car & $\begin{array}{l}\text { Pot. Acc. } \\
\text { Distance }\end{array}$ & Pot. Acc. car & Pot. Acc. car + PT & $\begin{array}{l}\text { Pot. Acc. } \\
\text { Composite }\end{array}$ \\
\hline & Model 1 & Model 2 & Model 3 & Model 4 & Model 5 & Model 6 & Model 7 & Model 8 & Model 9 & Model 10 \\
\hline Prox Basic Serv & $0.93 * *$ & $0.85 * *$ & $0.76^{* * *}$ & $0.81 * *$ & $0.81 * *$ & $0.86^{* *}$ & $0.92 * *$ & $0.91 * *$ & $0.90^{* *}$ & $0.87 * *$ \\
\hline Prox Pr. Schools & $0.10 * *$ & $0.10 * *$ & $0.11 * *$ & 0.11 ** & $0.10^{* *}$ & $0.10^{* * *}$ & $0.10^{* *}$ & $0.10^{* *}$ & $0.10^{* * *}$ & 0.10 ** \\
\hline Prox Sec. Schools & $0.17 * *$ & $0.15 * *$ & $0.11 * *$ & $0.11^{* *}$ & $0.11 * *$ & $0.13^{* *}$ & $0.07 * *$ & $0.10 * *$ & $0.09^{* *}$ & $0.08 * *$ \\
\hline$\% \mathrm{HLM}^{*} \mathrm{rev} 1$ & $2.53 * *$ & $2.14 * *$ & 0.06 & $0.08^{* *}$ & -0.07 & $0.14 * *$ & $0.59^{* *}$ & $0.62 * *$ & $0.74 * *$ & $0.32 * *$ \\
\hline$\% \mathrm{HLM} * \mathrm{rev} 2$ & $1.75 * *$ & $1.31 * *$ & $-0.79 * *$ & $-0.76 * *$ & $-0.91 * *$ & $-0.68 * *$ & $-0.26^{* * *}$ & $-0.22 * *$ & -0.09 & $-0.52^{* *}$ \\
\hline$\% \mathrm{HLM} * \mathrm{rev} 3$ & $1.17 * *$ & $0.69 * *$ & $-1.37 * *$ & $-1.31 * *$ & $-1.46^{* *}$ & $-1.25 * *$ & $-0.77 * *$ & $-0.74 * *$ & $-0.61 * *$ & $-1.06 * *$ \\
\hline$\% \mathrm{HLM}^{*} \mathrm{rev} 4$ & $1.15^{* *}$ & $0.72 * *$ & $-1.68 * *$ & $-1.46 * *$ & $-1.61^{* *}$ & $-1.58^{* *}$ & $-0.63 * *$ & $-0.57 * *$ & $-0.39 * *$ & $-0.98^{* *}$ \\
\hline$\%$ HLM*rev5 & $-0.28 * *$ & $-0.26^{* *}$ & $-2.74 * *$ & $-2.57 * *$ & $-2.75^{* *}$ & $-2.49 * *$ & $-1.85^{* *}$ & $-1.78 * *$ & $-1.62 * *$ & $-2.12 * *$ \\
\hline$\%$ rev3*rev3 & $1.72 * *$ & $1.93 * *$ & $2.99^{* *}$ & $3.15^{* *}$ & $3.24 * *$ & $2.94 * *$ & $3.09 * *$ & $2.85^{* *}$ & $2.88^{* *}$ & $2.99 * *$ \\
\hline$\%$ rev4*rev4 & $6.06 * *$ & $7.42 * *$ & $5.29 * *$ & $6.35^{* *}$ & $6.24 * *$ & $5.22^{* *}$ & $8.75^{* *}$ & $8.54 * *$ & $8.81^{* *}$ & $8.15 * *$ \\
\hline$\%$ rev5*rev5 & $2.26 * *$ & $3.67 * *$ & $3.09 * *$ & $3.30^{* *}$ & $3.18^{* * *}$ & $2.92^{* *}$ & $3.77^{* *}$ & $3.67 * *$ & $3.71 * *$ & $3.70 * *$ \\
\hline Housing price & $1.60 * *$ & $0.60 * *$ & $-0.97 * *$ & $-1.16 * *$ & $-1.24 * *$ & $-0.29 * *$ & $-1.07 * *$ & $-0.77 * *$ & $-0.75 * *$ & $-0.93 * *$ \\
\hline Accessibility & - & - & $-0.10^{* *}$ & $-0.06 * *$ & $-0.05 * *$ & $1.49^{* *}$ & $0.61^{* *}$ & $0.79 * *$ & $0.69 * *$ & $0.54 * *$ \\
\hline Accessibility 2 & - & - & - & - & $-0.02 * *$ & - & & - & $0.19^{* *}$ & - \\
\hline Motorway & - & $-0.17^{*}$ & - & - & - & - & & - & - & - \\
\hline Metro & - & $0.79^{*}$ & - & - & - & - & & - & - & - \\
\hline Tramway & - & $0.69^{*}$ & - & - & - & - & & - & - & - \\
\hline Railway station & - & $0.09^{*}$ & - & - & - & - & & - & - & - \\
\hline Observations & 102,940 & 102,940 & 102,940 & 102,940 & 102,940 & 102,940 & 102,940 & 102,940 & 102,940 & 102,940 \\
\hline Log of likelihood zero & $-200,312$ & $-200,312$ & $-200,312$ & $-200,312$ & $-200,312$ & $-200,312$ & $-200,312$ & $-200,312$ & $-200,312$ & $-200,312$ \\
\hline Log of likelihood (LL) & $-163,899$ & $-154,006$ & $-153,267$ & $-152,671$ & $-152,274$ & $-155,676$ & $-149,305$ & $-150,037$ & $-149,914$ & $-149,491$ \\
\hline Rho-squared & .182 & .231 & .235 & .238 & .240 & .223 & .255 & .251 & .252 & .254 \\
\hline \multirow{2}{*}{ Likelihood ratio test ${ }^{+}$} & \multirow{2}{*}{ Base } & vs 1 & vs 1 & vs 1 & vs 5 & vs 1 & vs 1 & vs 1 & vs 8 & vs 1 \\
\hline & & $19,784 * *$ & $21,262 * *$ & $22,455^{* *} *$ & $793 * *$ & $16,445^{* *}$ & $29,186 * *$ & $27,723 * *$ & $246 * *$ & $28,815^{* *}$ \\
\hline
\end{tabular}


Table 8 Parameters and statistical tests of the models including individual taste variation and potential accessibility measures

\begin{tabular}{|c|c|c|c|c|c|c|c|c|c|c|c|c|}
\hline & $\begin{array}{l}\text { Dist. centre * } \\
\text { Nb Indiv. }\end{array}$ & $\begin{array}{l}\text { Dist. centre * } \\
\text { HH Education. }\end{array}$ & $\begin{array}{l}\text { Dist. centre. * } \\
\text { HH Status. }\end{array}$ & $\begin{array}{l}\text { Pot. Acc. Dist. * } \\
\text { Nb Indiv. }\end{array}$ & $\begin{array}{l}\text { Pot. Acc. Dist * } \\
\text { HH Education. }\end{array}$ & $\begin{array}{l}\text { Pot. Acc. Dist. * } \\
\text { HH Status. }\end{array}$ & $\begin{array}{l}\text { Pot. Acc. car * } \\
\text { Nb Indiv. }\end{array}$ & $\begin{array}{l}\text { Pot. Acc. car * } \\
\text { HH Education }\end{array}$ & $\begin{array}{l}\text { Pot. Acc. car * } \\
\text { HH Status }\end{array}$ & $\begin{array}{c}\text { Pot. Acc. } \\
\text { Composite * Nb } \\
\text { indiv. } \\
\end{array}$ & $\begin{array}{c}\text { Pot. Acc. } \\
\text { Composite *HH } \\
\text { Education } \\
\end{array}$ & $\begin{array}{c}\text { Pot. Acc. } \\
\text { Composite * HH } \\
\text { Status } \\
\end{array}$ \\
\hline & Model 3-1 & Model 3-2 & Model 3 - 3 & Model 7 - 1 & Model 7 - 2 & Model 7 - 3 & Model 8 - 1 & Model 8 - 2 & Model 8 - 3 & Model $10-1$ & Model 10 - 2 & Model 10 - 3 \\
\hline Prox Basic Serv & 0.79 ** & $0.83 * *$ & $0.83 * *$ & $0.93 * *$ & $0.93 * *$ & $0.95^{* *}$ & $0.91 * *$ & $0.92 * *$ & $0.95 * *$ & $0.89 * *$ & $0.90^{* * *}$ & $0.92 * *$ \\
\hline Prox Pr. Schools & $0.11 * *$ & $0.11 * *$ & $0.11 * *$ & $0.09 * *$ & $0.10^{* *}$ & $0.10^{* *}$ & $0.10^{* *}$ & $0.10^{* *}$ & $0.10^{* *}$ & $0.10^{* *}$ & $0.10^{* * *}$ & $0.10^{* *}$ \\
\hline Prox Sec. Schools & $0.11 * *$ & $0.12 * *$ & $0.11 * *$ & $0.07 * *$ & $0.08 * *$ & $0.08 * *$ & $0.10 * *$ & $0.11 * *$ & $0.11 * *$ & $0.08 * *$ & $0.09 * *$ & $0.09 * *$ \\
\hline$\% \mathrm{HLM}^{*} \mathrm{rev} 1$ & 0.01 & $0.60 * *$ & $0.14 * *$ & $0.69 * *$ & $1.07 * *$ & $0.82 * *$ & $0.69 * *$ & $1.05 * *$ & $0.83 * *$ & $0.39 * *$ & $0.84 * *$ & $0.55^{* * *}$ \\
\hline$\% \mathrm{HLM}^{*}{ }^{\mathrm{rev} 2}$ & $-0.80 * *$ & $-0.21^{* *}$ & $-0.78 * *$ & $-0.15 * *$ & $0.25^{* *}$ & $-0.15^{* *}$ & $-0.12 * *$ & $0.23 * *$ & $-0.11 * *$ & $-0.42 * *$ & 0.02 & $-0.40^{* *}$ \\
\hline$\% \mathrm{HLM}^{*}{ }^{\mathrm{rev}} 3$ & $-1.36 * *$ & -0.80 ** & $-1.37 * *$ & $-0.65 * *$ & $-0.27^{* *}$ & $-0.68 * *$ & $-0.64 * *$ & $-0.31 * *$ & $-0.66 * *$ & $-0.95^{* *}$ & $-0.53^{* *}$ & $-0.96^{* *}$ \\
\hline$\% \mathrm{HLM}^{*}$ rev4 & $-1.54 * *$ & $-1.02 * *$ & $-1.55 * *$ & $-0.42 * *$ & $-0.08^{* *}$ & $-0.44 * *$ & $-0.38 * *$ & $-0.11^{*}$ & $-0.41^{* *}$ & $-0.75 * *$ & $-0.41 * *$ & $-0.77 * *$ \\
\hline$\% \mathrm{HLM}^{*}$ rev5 & $-2.43 * *$ & $-2.29 * *$ & $-2.53 * *$ & $-1.48 * *$ & $-1.44 * *$ & $-1.62 * *$ & $-1.43 * *$ & $-1.44 * *$ & $-1.56^{* *}$ & $-1.73^{* *}$ & $-1.70 * *$ & $-1.85^{* *}$ \\
\hline$\%$ rev3*rev3 & $3.02 * *$ & $2.76 * *$ & $2.71 * *$ & $3.12 * *$ & $2.81 * *$ & $2.76^{* *}$ & $2.85^{* *}$ & $2.61 * *$ & $2.52 * *$ & $2.99 * *$ & $2.70^{* *}$ & $2.65^{* *}$ \\
\hline$\%$ rev $4 *_{\text {rev }} 4$ & $5.75^{* *}$ & $5.92 * *$ & $5.83 * *$ & $8.95 * *$ & $8.73 * *$ & $8.96 * *$ & $8.70 * *$ & $8.55^{* *}$ & $8.71 * *$ & $8.41 * *$ & $8.26 * *$ & $8.43 * *$ \\
\hline$\%$ rev5 5 rev5 & $3.46^{* *}$ & $2.89 * *$ & $3.39 * *$ & $4.09^{* *}$ & $3.55^{* *}$ & $3.95 * *$ & $3.96^{* *}$ & $3.50^{* *}$ & $3.85 * *$ & $4.00^{* *}$ & $3.50^{* * *}$ & $3.90^{* * *}$ \\
\hline Housing price & $-1.03 * *$ & $-0.52 * *$ & $-1.08^{* *}$ & $-1.05^{* *}$ & $-0.59^{* *}$ & $-1.05 * *$ & $-0.76 * *$ & $-0.39 * *$ & $-0.76 * *$ & $-0.91 * *$ & $-0.48 * *$ & $-0.93^{* *}$ \\
\hline Acc $* 1$ or 2 indiv & $-0.13 * *$ & & & $0.73 * *$ & & & $0.96^{* *}$ & - & - & $0.65 * *$ & - & - \\
\hline Acc $* 3+$ Indiv & $-0.06 * *$ & & & $0.33^{* *}$ & & & $0.38^{* *}$ & - & - & $0.28 * *$ & - & - \\
\hline Acc $*$ Mid Educ & & $-0.10^{* *}$ & & & $0.63 * *$ & & - & $0.85^{* *}$ & - & - & $0.57 * *$ & - \\
\hline Acc * Low Educ & & $-0.04 * *$ & & & $0.26^{* *}$ & & - & $0.32 * *$ & - & - & $0.23 * *$ & - \\
\hline Acc $*$ High Educ & & $-0.15^{* *}$ & & & $0.75^{* *}$ & & - & $0.98^{* *}$ & - & - & $0.66 * *$ & - \\
\hline Acc * Act No Stable & & & $-0.15^{* *}$ & & & $0.84 * *$ & - & - & $1.10^{* *}$ & - & - & $0.75^{* *}$ \\
\hline Acc * Act Stable & & & $-0.08 * *$ & & & $0.50^{* *}$ & - & - & $0.63 * *$ & - & - & $0.43 * *$ \\
\hline Acc $*$ No active & & & $-0.09^{* *}$ & & & $0.55^{* *}$ & - & - & $0.70^{* *}$ & - & - & $0.49^{* *}$ \\
\hline Acc $*$ Student & & & $-0.39 * *$ & & & $1.32 * *$ & - & - & $1.85 * *$ & - & - & $1.38^{* * *}$ \\
\hline Observations & 102,940 & 102,940 & 102,940 & 102,940 & 102,940 & 102,940 & 102,940 & 102,940 & 102,940 & 102,940 & 102,940 & 102,940 \\
\hline Log of likelihood zero & $-200,312$ & $-200,312$ & $-200,312$ & $-200,312$ & $-200,312$ & $-200,312$ & $-200,312$ & $-200,312$ & $-200,312$ & $-200,312$ & $-200,312$ & $-200,312$ \\
\hline Log of likelihood (LL) & $-150,704$ & $-151,429$ & $-148,923$ & $-146,391$ & $-147,506$ & $-145,726$ & $-146,993$ & $-148,302$ & $-146,207$ & $-146,507$ & $-148,127$ & $-145,315$ \\
\hline Rho-squared & .248 & .244 & .257 & .269 & .264 & .273 & .266 & .260 & .270 & .269 & .261 & .275 \\
\hline \multirow{2}{*}{ Likelihood ratio test $^{+}$} & vs 3 & vs 3 & vs 3 & vs 7 & vs 7 & vs 7 & vs 8 & vs 8 & vs 8 & vs 10 & vs 10 & vs 10 \\
\hline & $5,126^{* * *}$ & $3,676^{* *}$ & $8,689 * *$ & $5,828 * *$ & $3,598^{* *}$ & $7,158^{* * *}$ & $5,842 * *$ & $3,223 * *$ & $7,413^{* *}$ & $5,968 * *$ & $2,729 * *$ & $8,352^{* *}$ \\
\hline
\end{tabular}


Table 9 Capacity to replicate the observed market share of the models using all accessibility measures

\begin{tabular}{|c|c|c|c|c|c|c|c|c|c|c|c|c|c|c|c|c|c|c|c|c|c|}
\hline & \multirow{3}{*}{ Observed } & \multirow{2}{*}{\multicolumn{2}{|c|}{$\begin{array}{c}\begin{array}{c}\text { Base model } \\
\text { (no accessibility) }\end{array} \\
\text { Model } 1\end{array}$}} & \multirow{2}{*}{\multicolumn{2}{|c|}{$\begin{array}{c}\begin{array}{c}\text { Transport Infr. } \\
\text { Proximity }\end{array} \\
\text { Model } 2\end{array}$}} & \multirow{2}{*}{\multicolumn{2}{|c|}{$\begin{array}{c}\text { Dist. to centre } \\
\text { Model } 3\end{array}$}} & \multirow{2}{*}{\multicolumn{2}{|c|}{$\begin{array}{c}\text { Time to centre } \\
\text { Model } 4\end{array}$}} & \multirow{2}{*}{\multicolumn{2}{|c|}{$\begin{array}{c}\begin{array}{c}\text { Time to centre }+2^{\text {nd }} \\
\text { centres }\end{array} \\
\text { Model } 5\end{array}$}} & \multicolumn{2}{|c|}{ Cumm. Opp. car } & \multicolumn{2}{|c|}{ Pot. Acc. Distance } & \multicolumn{2}{|c|}{ Pot. Acc. car } & \multicolumn{2}{|c|}{ Pot. Acc. car + PT } & \multicolumn{2}{|c|}{ Pot. Acc. Composite } \\
\hline & & & & & & & & & & & & & & & & & & & & & \\
\hline \multirow[b]{2}{*}{$\begin{array}{l}\text { Centre (Lyon - } \\
\text { Villeurbane) }\end{array}$} & & Rep & Diff & Rep & Diff & Rep & Diff & Rep & Diff & Rep & Diff & Rep & Diff & Rep & Diff & Rep & Diff & Rep & Diff & Rep & Diff \\
\hline & $55.0 \%$ & $37.8 \%$ & $-17.3 \%$ & $39.8 \%$ & $-15.3 \%$ & $45.8 \%$ & $-9.3 \%$ & $47.8 \%$ & $-7.3 \%$ & $47.4 \%$ & $-7.6 \%$ & $43.7 \%$ & $-11.4 \%$ & $56.3 \%$ & $1.2 \%$ & $54.5 \%$ & $-0.6 \%$ & $55.0 \%$ & $0.0 \%$ & $53.1 \%$ & $-1.9 \%$ \\
\hline East Areas & $11.0 \%$ & $11.9 \%$ & $0.9 \%$ & $15.7 \%$ & $4.7 \%$ & $15.7 \%$ & $4.7 \%$ & $14.0 \%$ & $3.0 \%$ & $14.5 \%$ & $3.4 \%$ & $17.6 \%$ & $6.6 \%$ & $12.2 \%$ & $1.2 \%$ & $12.3 \%$ & $1.3 \%$ & $12.1 \%$ & $1.1 \%$ & $13.9 \%$ & $2.8 \%$ \\
\hline West Areas & $11.1 \%$ & $15.4 \%$ & $4.3 \%$ & $17.1 \%$ & $5.9 \%$ & $15.3 \%$ & $4.2 \%$ & $14.4 \%$ & $3.3 \%$ & $14.4 \%$ & $3.3 \%$ & $15.9 \%$ & $4.8 \%$ & $9.2 \%$ & $-1.9 \%$ & $9.7 \%$ & $-1.5 \%$ & $9.3 \%$ & $-1.8 \%$ & $10.8 \%$ & $-0.4 \%$ \\
\hline $2^{\text {nd }}$ Belt & $8.0 \%$ & $12.8 \%$ & $4.8 \%$ & $11.9 \%$ & $3.9 \%$ & $11.5 \%$ & $3.5 \%$ & $10.2 \%$ & $2.2 \%$ & $10.3 \%$ & $2.3 \%$ & $10.3 \%$ & $2.3 \%$ & $7.1 \%$ & $-0.8 \%$ & $7.4 \%$ & $-0.5 \%$ & $7.4 \%$ & $-0.6 \%$ & $7.3 \%$ & $-0.7 \%$ \\
\hline \multirow[t]{2}{*}{$3^{\text {rd }}$ Belt } & $14.8 \%$ & $22.0 \%$ & $7.2 \%$ & $15.6 \%$ & $0.8 \%$ & $11.7 \%$ & $-3.1 \%$ & $13.6 \%$ & $-1.2 \%$ & $13.3 \%$ & $-1.5 \%$ & $12.5 \%$ & $-2.3 \%$ & $15.2 \%$ & $0.4 \%$ & $16.1 \%$ & $1.2 \%$ & $16.2 \%$ & $1.4 \%$ & $14.9 \%$ & $0.1 \%$ \\
\hline & & RMSE & $8.87 \%$ & RMSE & $7.83 \%$ & RMSE & $5.42 \%$ & RMSE & $3.97 \%$ & RMSE & $4.20 \%$ & RMSE & $6.43 \%$ & RMSE & $1.21 \%$ & RMSE & $1.09 \%$ & RMSE & $1.16 \%$ & RMSE & $1.57 \%$ \\
\hline
\end{tabular}

Table 10 Capacity to replicate the observed market share of the models including individual taste variation and potential accessibility measures

\begin{tabular}{|c|c|c|c|c|c|c|c|c|c|c|c|c|c|c|c|c|c|c|c|c|c|c|c|c|c|}
\hline & \multirow{3}{*}{ Observ. } & \multirow{2}{*}{\multicolumn{2}{|c|}{$\begin{array}{l}\begin{array}{c}\text { Dist. centre * } \\
\text { Nb Indiv. }\end{array} \\
\text { Model } 3 \text { - } 1\end{array}$}} & \multirow{2}{*}{\multicolumn{2}{|c|}{$\begin{array}{c}\begin{array}{c}\text { Dist. centre * } \\
\text { HH Education. }\end{array} \\
\text { Model } 3 \text { - } 2\end{array}$}} & \multirow{2}{*}{\multicolumn{2}{|c|}{$\begin{array}{l}\begin{array}{c}\text { Dist. centre. * } \\
\text { HH Status. }\end{array} \\
\text { Model } 3 \text { - } 3\end{array}$}} & \multirow{2}{*}{\multicolumn{2}{|c|}{$\begin{array}{c}\begin{array}{c}\text { Pot. Acc. Dist. * } \\
\text { Nb Indiv. }\end{array} \\
\text { Model } 7 \text { - } 1\end{array}$}} & \multirow{2}{*}{\multicolumn{2}{|c|}{$\begin{array}{c}\begin{array}{c}\text { Pot. Acc. Dist * } \\
\text { HH Education. }\end{array} \\
\text { Model } 7 \text { - } 2\end{array}$}} & \multirow{2}{*}{\multicolumn{2}{|c|}{$\begin{array}{c}\begin{array}{c}\text { Pot. Acc. Dist. * } \\
\text { HH Status. }\end{array} \\
\text { Model } 7 \text { - } 3\end{array}$}} & \multirow{2}{*}{\multicolumn{2}{|c|}{$\begin{array}{l}\begin{array}{l}\text { Pot. Acc. car * } \\
\text { Nb Indiv. }\end{array} \\
\text { Model } 8 \text { - } 1\end{array}$}} & \multirow{2}{*}{\multicolumn{2}{|c|}{$\begin{array}{c}\begin{array}{c}\text { Pot. Acc. car * } \\
\text { HH Education }\end{array} \\
\text { Model } 8 \text { - } 2 \\
\end{array}$}} & \multirow{2}{*}{\multicolumn{2}{|c|}{$\begin{array}{c}\begin{array}{c}\text { Pot. Acc. car * } \\
\text { HH Status }\end{array} \\
\text { Model } 8 \text { - } 3 \\
\end{array}$}} & \multirow{2}{*}{\multicolumn{2}{|c|}{$\begin{array}{c}\text { Pot. Acc. Compos. * } \\
\text { Nb indiv. } \\
\text { Model } 10-1\end{array}$}} & \multirow{2}{*}{\multicolumn{2}{|c|}{$\begin{array}{c}\begin{array}{c}\text { Pot. Acc. Compos. * } \\
\text { Education }\end{array} \\
\text { Model } 10-2 \\
\end{array}$}} & \multirow{2}{*}{\multicolumn{2}{|c|}{$\begin{array}{c}\text { Pot. Acc. Compos. * } \\
\text { HH Status } \\
\text { Model } 10-3\end{array}$}} \\
\hline & & & & & & & & & & & & & & & & & & & & & & & & & \\
\hline & & Rep. & Diff. & Rep. & Diff. & Rep. & Diff. & Rep. & Diff. & Rep. & Diff. & Rep. & Diff. & Rep. & Diff. & Rep. & Diff. & Rep. & Diff. & ep. & Diff. & Rep. & Diff. & Rep. & Diff. \\
\hline \multirow{2}{*}{$\begin{array}{l}\text { Centre (Lyon - } \\
\text { Villeurbanne) } \\
\text { East Areas }\end{array}$} & $55 \%$ & $46.3 \%$ & $-8.8 \%$ & $45.4 \%$ & $-9.7 \%$ & $46.9 \%$ & $-8.2 \%$ & $56.2 \%$ & $1.1 \%$ & $53.8 \%$ & $-1.3 \%$ & $56.3 \%$ & $1.2 \%$ & $54.5 \%$ & $-0.6 \%$ & $52.5 \%$ & $-2.6 \%$ & $54.5 \%$ & $-0.6 \%$ & $54.2 \%$ & $-0.9 \%$ & $52.0 \%$ & $-3.0 \%$ & $54.4 \%$ & $-0.7 \%$ \\
\hline & $11 \%$ & $15.5 \%$ & $4.5 \%$ & $14.6 \%$ & $3.6 \%$ & $15.1 \%$ & $4.1 \%$ & $11.9 \%$ & $0.9 \%$ & $11.8 \%$ & $0.8 \%$ & $11.9 \%$ & $0.8 \%$ & $12.0 \%$ & $1.0 \%$ & $12.0 \%$ & $1.0 \%$ & $12.0 \%$ & $0.9 \%$ & $13.3 \%$ & $2.3 \%$ & $13.0 \%$ & $2.0 \%$ & $13.1 \%$ & $2.1 \%$ \\
\hline West Areas & $11 \%$ & $15.1 \%$ & $4.0 \%$ & $14.8 \%$ & $3.7 \%$ & $14.6 \%$ & $3.4 \%$ & $9.0 \%$ & $-2.1 \%$ & $9.4 \%$ & $-1.7 \%$ & $8.9 \%$ & $-2.2 \%$ & $9.5 \%$ & $-1.6 \%$ & $9.8 \%$ & $-1.3 \%$ & $9.4 \%$ & $-1.8 \%$ & $10.6 \%$ & $-0.6 \%$ & $10.8 \%$ & $-0.3 \%$ & $10.3 \%$ & $-0.8 \%$ \\
\hline $2^{\text {nd }}$ Belt & $8 \%$ & $11.0 \%$ & $3.1 \%$ & $10.8 \%$ & $2.8 \%$ & $11.0 \%$ & $3.0 \%$ & $7.3 \%$ & $-0.7 \%$ & $7.8 \%$ & $-0.2 \%$ & $7.2 \%$ & $-0.7 \%$ & $7.5 \%$ & $-0.4 \%$ & $8.0 \%$ & $0.0 \%$ & $7.5 \%$ & $-0.4 \%$ & $7.4 \%$ & $-0.5 \%$ & $8.0 \%$ & $0.0 \%$ & $7.4 \%$ & $-0.6 \%$ \\
\hline \multirow[t]{2}{*}{$3^{\text {rd }}$ Belt } & $15 \%$ & $12.0 \%$ & $-2.8 \%$ & $14.4 \%$ & $-0.4 \%$ & $12.5 \%$ & $-2.3 \%$ & $15.7 \%$ & $0.9 \%$ & $17.2 \%$ & $2.4 \%$ & $15.8 \%$ & $0.9 \%$ & $16.5 \%$ & $1.6 \%$ & $17.7 \%$ & $2.9 \%$ & $16.6 \%$ & $1.8 \%$ & $14.5 \%$ & $-0.3 \%$ & $16.2 \%$ & $1.4 \%$ & $14.8 \%$ & $0.0 \%$ \\
\hline & & RMSE & $5.11 \%$ & RMSE & $5.07 \%$ & RMSE & $4.69 \%$ & RMSE & $1.25 \%$ & SE & $1.48 \%$ & RMSE & $1.32 \%$ & RMSE & $1.18 \%$ & RMSE & $1.86 \%$ & RMSE & $1.25 \%$ & RMSE & $1.14 \%$ & RMSE & $1.73 \%$ & RMSE & $1.07 \%$ \\
\hline
\end{tabular}




\section{Discussion}

The main result of this study is that accessibility remains a key variable in residential location choice modelling whatever is the measure. Even very simplistic measures of accessibility give significant results. The inclusion of accessibility in the model increases significantly its quality in all cases and corrects for the non-intuitive sign of housing price. Generally, the comparison of the different accessibility indicators has shown that the results are not radically different despite the quality differences. All the measures give consistent results, the parameters have stable signs and the selected household characteristics have the same sensitivity to all accessibility measures.

Between the measures that include the land-use component, the potential accessibility measure should be preferable even at its simplest form. On the contrary, the application of the cumulative opportunities measure should be made with care due to sensitivity to contour limit definition ${ }^{6}$. In our case, we obtained the best results for the limit of 12 minutes, but there is no behavioural evidence explaining this result.

If we consider that market share replication is an important indicator of model quality for simulation purposes, the best model is not the one with the highest rho-squared. Simple measures of accessibility without the land-use dimension are struggling to replicate the observed market shares. Tests show that even simple employment density is not able to capture this preference ${ }^{7}$. When there is a need for simulation, potential accessibility indicators are preferable, even the simplest ones (for example linear distance as a friction). The inclusion of individual taste variations is useful from an analysis point of view but it does not ameliorate the replication of the market shares. In some cases, it even deteriorates the results. This is due to the heterogeneity inside the selected household groups, which sometimes can be very important.

The analysis shows that when a household chooses a location, all the components of accessibility are important. The analysis of the ability of the model to replicate the observed market share reveals that models without accessibility measures fail to replicate the attractiveness of the centre. People choose

\footnotetext{
${ }^{6}$ We can provide by request more detailed analysis, which is not presented in this article.

${ }^{7}$ We can provide the detailed results by request
} 
to live in the city centre for the number of employment and activity participation opportunities. Accessibility measures, which integrate the combined effect of land-use and transportation, achieve to capture this preference.

\section{Conclusions}

The objective of this paper is to give some answers to the question of whether the type of the accessibility measure can influence the estimation results of a residential location choice model. The literature analysis has shown that there is an abundance of accessibility measures but their influence on residential choice behaviour is not easily identified (Blijie 2005). For our analysis, we have selected various measures, from very simplistic to more complex ones. Individual taste variation was introduced by interacting in the model household characteristics with accessibility. We analysed the ability of the different models to replicate the observations.

With regard to the debate around the significance of accessibility in residential location choice, we take the view that transportation and land-use modellers must integrate some sort of accessibility measure in their models. Omission of accessibility measures could lead to erroneous results. The measure it-self does not influence significantly statistical indicators of models quality. In case of absence of data, and especially when there is no simulation objective, the use of simple measures can be justified. However, the results of the forecast will be improved with the use of comprehensive measures. The inclusion of the land-use component is important, even if the transport dimension is simplified. If the objective is to assess transportation policies, where significant travel time changes are expected, a measure sensible to time or cost should be chosen. For simulation, individual characteristics interaction with accessibility should be introduced with care.

The results of our analysis show the importance of the land-use component into the accessibility analysis. From a policy point of view, decision makers should take into consideration that residential policies focusing only on transportation will not be sufficient to attract new households. While it is important to have fast transport means to reach different destinations, residents are searching for 
employment and activities near their homes. Residents are attracted not only by transportation facilities, but also by activities in which they can participate.

We perform our analysis on cross sectional data. It could be interesting to analyse the temporal and spatial transferability of these results. This work focus only on the employment opportunities, as a general proxy for various land-use opportunities. However, further analysis is needed for different activity purposes. Works focusing on this issue should resolve the problems of multicollinearity between different accessibility to activity measures. Last, the accessibility measure applied in this study has some limitations. Integration of more transportation modes might be important if we want to analyse the inclusion of more environmentally friendly transportation modes such as bicycle or walk.

\section{Acknowledgments}

The authors wish to acknowledge the feedback from the participants of the European Association for Research in Transportation (hEART) conference of 2016 in Delft and the NECTAR workshop of 2016 in Paris. The corresponding author acknowledges the financial support of a doctoral scholarship award by the Region of Auvergne-Rhône-Alpes.

\section{Conflict of interest statement}

On behalf of all authors, the corresponding author states that there is no conflict of interest.

\section{Authors' contribution}

- I Baraklianos: Literature Search and Review, Model Adaptation, Evaluation Method Development, Manuscript Writing

- L Bouzouina: Manuscript Writing and Editing, Literature Search, Research Question Conception

- P Bonnel: Manuscript Writing and Editing, Research Question Conception, General Guideline

- H Aissaoui: Model Conception, Data Preparation 


\section{References}

Acheampong, R.A., Silva, E.A.: Land use - transport interaction modeling : A review of the literature and future research directions. J. Transp. Land Use. 8, 11-38 (2015)

Aissaoui, H., Bouzouina, L., Bonnel, P.: Choix de localisation résidentielle, entre contraintes du marché et préférences individuelles : application à l'aire urbaine de Lyon 1999. Rev. d'Economie Régionale Urbaine. 4, 629-656 (2015)

Alonso, W.: Location and land use : toward a general theory of land rent. Harvard University Press, Cambridge, Mass. (1964)

Ben-Akiva, M., Lerman, S.: Discrete Choice Analysis: Theory and Application to Travel Demand. MIT Press, Cambridge, USA (1985)

Bhat, C.R., Carini, J., Misra, R.: Modeling the Generation and Organization of Household Activity Stops. Transp. Res. Rec. J. Transp. Res. Board. 1676, 153-161 (1999). doi:10.3141/1676-19

Blijie, B.: The impact of accessibility on residential choice : Empirical results of a discrete choice model. In: 45TH Congress of the European Regional Science Association (2005)

Boisjoly, G., El-Geneidy, A.M.: Daily fluctuations in transit and job availability: A comparative assessment of time-sensitive accessibility measures. J. Transp. Geogr. 52, 73-81 (2016). doi:10.1016/j.jtrangeo.2016.03.004

Bonnel, P., Bouzouina, L., Monchambert, G.: Croissance urbaine et accessibilité : intérêts et limites de l'approche par les densités dans une perspective de modélisation de l'usage du sol. Cybergeo Eur. J. Geogr. (2013)

Bouzouina, L., Cabrera-Delgado, J., Emmerich, G.: Inégalités d'accessibilité à l'emploi en Transport Collectif Urbain : Deux décennies d'évolutions en banlieue lyonnaise. Rev. d'Economie Régionale Urbaine. 1, 33-61 (2014)

Bunel, M., Tovar, E.: Key Issues in Local Job Accessibility Measurement: Different Models Mean Different Results. Urban Stud. 51, 1322-1338 (2014). doi:10.1177/0042098013495573

Cascetta, E., Cartenì, A., Montanino, M.: A behavioral model of accessibility based on the number of available opportunities. J. Transp. Geogr. 51, 45-58 (2016). doi:10.1016/j.jtrangeo.2015.11.002

Cho, E.J., Rodriguez, D. a, Song, Y.: The role of employment subcenters in residential location decisions. J. Transp. Land Use. 2, 121-151 (2008). doi:10.5198/jtlu.v3i1.194

Cordera, R., Coppola, P., dell'Olio, L., Ibeas, Á.: Is accessibility relevant in trip generation? Modelling the interaction between trip generation and accessibility taking into account spatial effects. Transportation (Amst). 44, 1577-1603 (2017). doi:10.1007/s11116-016-9715-5

Eliasson, J.: The Influence of Accessibility on Residential Location. In: Pagliara, F., Preston, J., and Simmons, D. (eds.) Residential Location Choice: Models and applications. pp. 137-164. Springer (2010)

Fox, J., Daly, A., Hess, S., Miller, E.: Temporal transferability of models of mode-destination choice for the Greater Toronto and Hamilton Area. J. Transp. Land Use. 7, 41 (2014). doi:10.5198/jtlu.v7i2.701

Frenkel, A., Bendit, E., Kaplan, S.: Residential location choice of knowledge-workers: The role of amenities, workplace and lifestyle. Cities. 35, 33-41 (2013). doi:10.1016/j.cities.2013.06.005

Geurs, K.T., Ritsema van Eck, J.R.: Accessibility measures: review and applications. Evaluation of accessibility impacts of land-use transport scenarios, and related social and economic impacts, (2001)

Geurs, K.T., van Wee, B.: Accessibility evaluation of land-use and transport strategies: review and research directions. J. Transp. Geogr. 12, 127-140 (2004). doi:10.1016/j.jtrangeo.2003.10.005

Guevara, C.A.: Critical assessment of five methods to correct for endogeneity in discrete-choice models. Transp. Res. Part A Policy Pract. 82, 240-254 (2015). doi:10.1016/j.tra.2015.10.005

Guo, J.Y., Bhat, C.R.: Residential Location Choice Modeling : Accommodating Sociodemographic, School Quality and Accessibility Effects., Austin (2001) 
Guo, J.Y., Bhat, C.R.: Operationalizing the concept of neighborhood: Application to residential location choice analysis. J. Transp. Geogr. 15, 31-45 (2007). doi:10.1016/j.jtrangeo.2005.11.001

Hägerstrand, T.: What About People in Regional Science ? 9th Eur. Congr. Reg. Sci. Assoc. 24, 7-21 (1970)

Handy, S.L., Niemeier, D.A.: Measuring accessibility: An exploration of issues and alternatives. Environ. Plan. A. 29, 1175-1194 (1997). doi:10.1068/a291175

Hansen, W.G.: How Accessibility Shapes Land Use. J. Am. Inst. Plann. 25, 73-76 (1959). doi:10.1080/01944365908978307

Hu, L.: Job accessibility and employment outcomes: which income groups benefit the most? Transportation (Amst). 44, 1421-1443 (2017). doi:10.1007/s11116-016-9708-4

Kryvobokov, M., Bouzouina, L.: Willingness to pay for accessibility under the conditions of residential segregation. Int. J. Strateg. Prop. Manag. 18, 101-115 (2014). doi:10.3846/1648715X.2013.864342

Lee, B.H.Y., Waddell, P., Wang, L., Pendyala, R.M.: Reexamining the influence of work and nonwork accessibility on residential location choices with a microanalytic framework. Environ. Plan. A. 42, 913-930 (2010). doi:10.1068/a4291

Lowry, I.S.: A model of metropolis. , California (1964)

McFadden, D.: Modelling the choice of residential location, http://cowles.econ.yale.edu/P/cd/d04b/d0477.pdf, (1977)

Millsap, A.: Location choice in early adulthood: Millennials versus Baby Boomers. Pap. Reg. Sci. (2016). doi:10.1111/pirs.12240

Nicolas, J.-P.: SIMBAD : un outil pour intégrer le développement durable dans les politiques publiques. In: Jean-Pierre, A. (ed.) Modéliser la ville : Formes urbaines et politiques de transport. pp. 120-164. Economica, Paris (2010)

Niedzielski, M.A., Eric Boschmann, E.: Travel Time and Distance as Relative Accessibility in the Journey to Work. Ann. Assoc. Am. Geogr. 104, 1156-1182 (2014). doi:10.1080/00045608.2014.958398

De Palma, A., Motamedi, K., Picard, N., Waddell, P.: Accessibility and Environmental Quality : Inequality in the Paris Housing Market. Eur. Transp. / Trasp. Eur. 36, 47-74 (2007)

Schirmer, P.M., Van Eggermond, M. a. B., Axhausen, K.W.: The role of location in residential location choice models: a review of literature. J. Transp. Land Use. 7, 3-21 (2014). doi:10.5198/jtlu.v7i2.740

Sener, I.N., Pendyala, R.M., Bhat, C.R.: Accommodating spatial correlation across choice alternatives in discrete choice models: an application to modeling residential location choice behavior. J. Transp. Geogr. 19 , 294-303 (2011). doi:10.1016/j.jtrangeo.2010.03.013

Srour, I., Kockelman, K., Dunn, T.: Accessibility Indices: Connection to Residential Land Prices and Location Choices. Transp. Res. Rec. 1805, 25-34 (2002). doi:10.3141/1805-04

Sytral: Enquête ménages déplacements 2006 de l'aire métropolitaine lyonnaise : Pricipaux résultats. , Lyon (2007)

Washington, S.P., Karlaftis, M.G., Mannering, F.L.: Statistical and econometric methods for transportation data analysis. CRC Press, New York (2011)

Wegener, M., Fürst, F.: Land-Use Transport Interaction: State of the Art. , Dortmund, (1999)

Zondag, B., de Bok, M., Geurs, K.T., Molenwijk, E.: Accessibility modeling and evaluation: The TIGRIS XL land-use and transport interaction model for the Netherlands. Comput. Environ. Urban Syst. 49, 115-125 (2015). doi:10.1016/j.compenvurbsys.2014.06.001

Zondag, B., Pieters, M.: Influence of Accessibility on Residential Location Choice. Transp. Res. Rec. J. Transp. Res. Board. 1902, 63-70 (2005). doi:10.3141/1902-08 